\title{
Indicators of healthy work environments - a systematic review
}

\author{
Per Lindberg ${ }^{\mathrm{a}, \mathrm{b}^{*}}$ \& Eva Vingård ${ }^{\mathrm{a}}$ \\ ${ }^{a}$ Occupational and Environmental Medicine, Department of Medical Sciences, Uppsala University, Sweden \\ ${ }^{\mathrm{b}}$ Centre for musculoskeletal research, Faculty of Health and Occupational Studies, University of Gävle, Sweden
}

\begin{abstract}
The purpose of this study was to systematically review the scientific literature and search for indicators of healthy work environments. A number of major national and international databases for scientific publication were searched for research addressing indicators of healthy work environments. Altogether 19768 publications were found. After excluding duplicates, non-relevant publications, or publications that did not comply with the inclusion criteria 24 peer-reviewed publications remained to be included in this systematic review. Only one study explicitly addressing indicators of healthy work environments was found. That study suggested that the presence of stress management programs in an organization might serve as indicator of a 'good place to work', as these organizations were more likely to offer programs that encouraged employee well-being, safety and skill development than those without stress management programs. The other 23 studies either investigated employee's views of what constitute a healthy workplace or were guidelines for how to create such a workplace. Summarizing, the nine most pronounced factors considered as important for a healthy workplace that emerged from these studies were, in descending order: collaboration/teamwork: growth and development of the individual; recognition; employee involvement; positive, accessible and fair leader; autonomy and empowerment; appropriate staffing; skilled communication; and safe physical work.
\end{abstract}

Keywords: Healthy work, healthy workplace, healthy organization, guidelines, employee

\section{Introduction}

The interest in medical science has until now mainly focused on how and why certain individuals become diseased, i.e. on pathogenesis. For the individual, the workplace and society, there would be considerable gains if the number of people suffering from physical and mental disorders could be reduced. Traditionally within occupational health this has been done by treating illnesses and, by suspicion of causative elements, eliminating or reducing identified risk factors at work. This is still the first choice in trying to achieve a sustainable working life. However, despite legislation in the field of work environment, both on national and international level, a century of labour inspections, and the efforts of thousands of occupational health personnel, still $21 \%$ of the Swedish women and $15 \%$ of the Swedish men reported in 2010 to have had work-related disorders other than accidents during the last twelve months [1]. It seems that the endeavours do not reach all the way.

Moreover, throughout many countries in the developed world the population is ageing, largely because of increasing life expectancy. One of the economic implications of this demographic change is that workers may need to work longer and retire later than they have done in recent years. Much needs to be done to ensure that work remains a positive experience for workers throughout their career trajectories, and that it does not damage their health [2].

\footnotetext{
* Corresponding author. E-mail: per.lindberg@hig.se; Phone: +46 26648759

Postal address: University of Gävle, SE-801 76 Gävle, Sweden
} 
A different and additional way of approaching the problem of work related morbidity is to look at and learn from what characterizes organisations with a low rate of long term sick listed. Some studies and reports have dealt with this [3-6]. Another approach has been to summarize empirical evidence from different research fields and create models of work environments supporting health, e.g. Danna and Griffin[7] and Grawitch et al [8]. Although several authors have tried to identify and describe the job and organizational characteristics associated with healthy organizations, there has been relatively little direct empirical research and no systematic analysis of a model of healthy work organization conducted [9]. Moreover, the specific dimensions comprising the major components of previous models have been either only minimally specified or not specified at all [ibid].

There does not seem to be any international agreement how to define the concept "healthy work environment" or rather there are different designations and aspects of this concept. For example, in Sweden this notion is more often called "good work environment", including physical, psychosocial and organizational conditions, and where the focus has been on the health of the employees. Thus, 'good work environment' could then be defined as work environments that on both short and long term do not cause work-related morbidity and adds to the individual's wellbeing. Lately there has also been a political approach in Sweden to integrate economical benefits of good work environments [10].

In international contexts concepts like "healthy work", "healthy workplace" or "healthy organizations" are more often discussed. These concepts center on the premise that it should be possible to identify the job and organizational characteristics of healthy organizations and that such organizations should have healthier and more productive workers. It also presupposes that it should be possible to distinguish healthy from unhealthy work systems. There seem to be some evidence for this, as well coherence in definitions. For example Sainforth [11] notes that research on healthy work organizations shows that some of the same work organization factors that affect employee outcomes such as quality of life and safety can also affect organizational outcomes such as profits and performance, and defines a "healthy work organization" as an organization that has both financial success and a healthy workforce. Sauter et al. [12] put it very clear and define a healthy workplace as any organization that "maximizes the integration of worker goals for wellbeing and com- pany objectives for profitability and productivity". A similar but more extensive definition is presented by Wilson et al [9]: 'A healthy organization is one characterized by intentional, systematic, and collaborative efforts to maximize employee well-being and productivity by providing well-designed and meaningful jobs, a supportive social-organizational environment, and accessible and equitable opportunities for career and work-life enhancement.

As far as the authors of this study are aware there has been no systematic approach to summarize present knowledge of what constitutes a healthy work environment and what might be its indicators. Knowledge of such indicators may serve as tools for e.g. employers, safety delegates, occupational health services, and labour inspectorates to operationalize ambitions to achieve healthy work places.

\section{Aim}

The purpose of this study was to systematically review the scientific literature and search for indicators of healthy work environments.

\section{Methods}

Regarding the diversity the concept 'healthy work environment' encompass and that no real consensus on a definition seems to exist, it was decided to have a broad and explorative approach for conducting the literature search. This position was also supported by personal experiences that there probably would be very few publications that directly would answer our research question. Hence, searches were designed to be inclusive, but at the same time a rigorous approach was required when it came to assessing the scientific worth of retrieved publications. Some initial pilot searches verified the appropriateness of the strategy.

As a consequence of this, databases covering different disciplines, methodologies and literature were chosen. The included databases were Academic Search Elite, ASSIA, Cinahl, Cochrane Library, Emerald, PubMed, PsychINFO, Scopus, SwePub, and Web of Science. These databases were systematically searched with different combinations of the key words "healthy OR good OR sound" AND "work OR workplace* OR work place* OR workforce* OR work force* OR worksite* OR work site* OR or- 
ganization* OR work organization* OR work environment* OR working environment* OR business*" separately and in combinations with "AND indicator* OR predictor*". The Swedish databases Libris, indikator* OR prediktor*". The search was limited to the years 1990 - 2011, humans, and following languages: English, Danish, German, Norwegian, and Swedish.

To be included in the study following criteria had to be fulfilled:

- the study involved work environmental issues. Papers about health promotion activities like diet, smoking cessation and physical activities were excluded;

- be published in peer-reviewed journals;

- original data or review articles, but excluding conference abstracts and proceedings because of a mostly shallow reviewing process. However, exceptions were made regarding policy papers, statements and guidance documents dealing with how to create good or healthy workplaces. Even if these were not original research papers they should be based on scientific data and of special interest for this study.
Scopus and SwePub were additionally searched with "god arbetsmiljö" (eng. "good work environment") separately and in combination with "AND

\section{Results}

Through the broad search strategy and partly overlapping databases 19768 publications were found. After excluding identical duplicates 7191 publications remained. Further, titles and abstracts of the identified articles were reviewed to determine the potential relevancy of the articles for our systematic review. By uncertainty the full article was retrieved and read. After excluding further duplicates and nonrelevant publications 24 articles remained and were included in this systematic review, see figure 1. Subsequently, references given in included publications were further examined.

Using content analysis, the included publications were grouped into three categories: 1 . Indicators, 2. Employee's views, and 3. Guidance documents. For each category a table is compiled displaying included articles and respective factors suggested to be associated with healthy work environments. (Due to limited space a summary of the included articles is not included, but can be obtained from the corresponding author.)

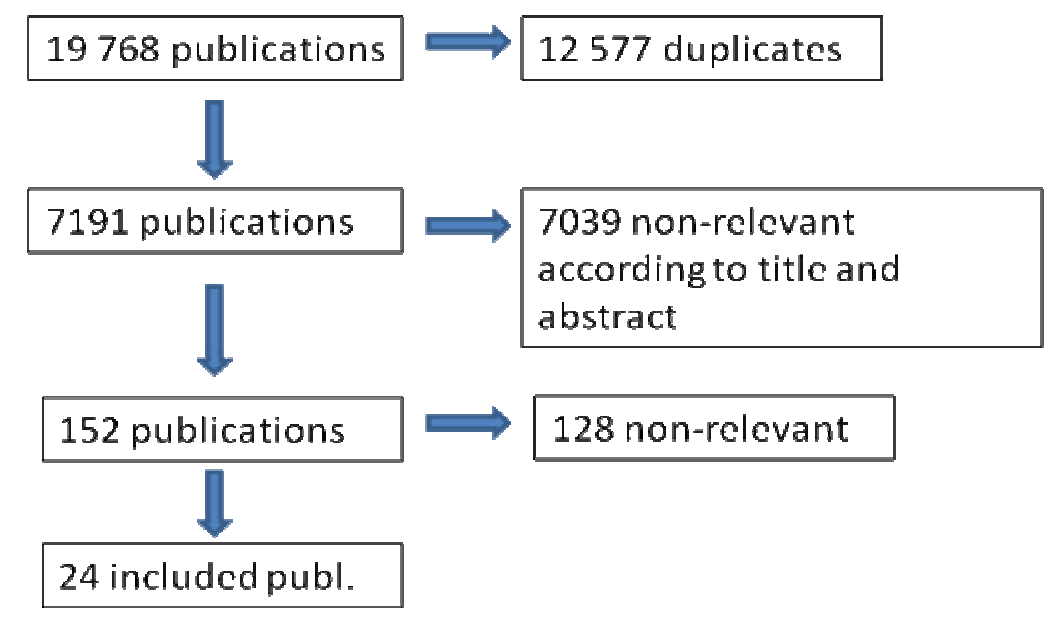

Figure 1 Results of the literature search 


\subsection{Indicators}

An indicator can be defined as a quantitative or qualitative factor or variable that provides a simple and reliable means to measure achievement, to reflect changes connected to an intervention, or to help assess the performance of a development actor [13].
Only one study was identified "that explicitly investigated indicators of healthy work environments [14]. The authors found that organizations that offered stress management programs also offered other programs to facilitate worker safety, health, wellbeing, and skill development. In this respect the presence of a stress management program appeared to be an indicator of a 'better place to work'.

Table 1

Factors at work described essential for a healthy work environment as described by employee

\begin{tabular}{|c|c|c|c|c|c|c|c|c|c|c|c|c|c|c|c|}
\hline Publica- & 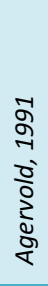 & 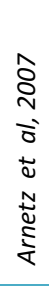 & 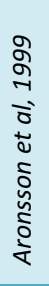 & 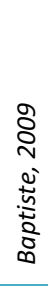 & 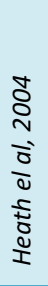 & 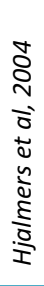 & 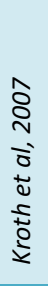 & 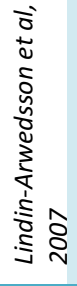 & 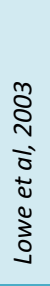 & 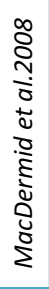 & 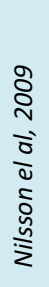 & 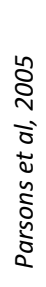 & 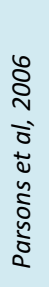 & 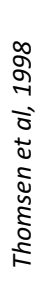 & 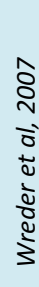 \\
\hline Use of personal qualities & & & $x$ & & & & & & & & & & & & \\
\hline In line w. personal values & & & $x$ & & & $x$ & & & & $x$ & & $x$ & $x$ & & \\
\hline Recognition & $x$ & $x$ & & & $x$ & & $x$ & & & & $x$ & & & & \\
\hline Treated w. respect & $x$ & & & & $x$ & & $x$ & $x$ & & $x$ & & & & $x$ & \\
\hline Autonomy, empowerment & & & $x$ & & $x$ & $x$ & $x$ & & $x$ & & & & & & \\
\hline Control at work & $x$ & & & & & & & & & & & & & & \\
\hline Role clarity & & & & & & & $x$ & & & & & & & & \\
\hline Clarity of expect. \& goals & & $x$ & & $x$ & & & $x$ & & & & & & & & \\
\hline Reward strategies & & & & $x$ & & & & & $x$ & & & & & & \\
\hline Growth \& development & $x$ & $x$ & $x$ & & & $x$ & $x$ & $x$ & & $x$ & $x$ & $x$ & $x$ & & $x$ \\
\hline Intellectually stimulating & & & & & & $x$ & & & & & & & & & \\
\hline Employee involvement & $x$ & $x$ & $x$ & & $x$ & $x$ & $x$ & $x$ & & & & & & & \\
\hline Collaboration/teamwork & $x$ & & & $x$ & $x$ & & $x$ & $x$ & & $x$ & & $x$ & $x$ & $x$ & $x$ \\
\hline Skilled communication & & & & $x$ & $x$ & & $x$ & $x$ & $x$ & $x$ & & & & & \\
\hline Quick problem solving & & & & & & & $x$ & & & & & & & & \\
\hline Pos. accessible, fair leader & $x$ & & & $x$ & $x$ & & $x$ & & & $x$ & & & & $x$ & $x$ \\
\hline Positive \& social climate & $x$ & $x$ & & & $x$ & & $x$ & $x$ & & & $x$ & & & & \\
\hline Reasonable work load & & $x$ & & & & & & & & $x$ & & & & $x$ & \\
\hline Work content & & & & & & & & & & & $x$ & $x$ & $x$ & & \\
\hline Safe physical work & & & & & & & $x$ & $x$ & & $x$ & & $x$ & $x$ & & \\
\hline Appropriate staffing & & & & & & & $x$ & $x$ & $x$ & & & $x$ & $x$ & & \\
\hline Adm./personal support & & & & & & & & & & & & $x$ & $x$ & $x$ & \\
\hline Working time schedule & & & & $x$ & & & & $x$ & & $x$ & & & & & \\
\hline Work-life balance & & & & & & & & & & & & & & & \\
\hline Relations to stakeholders & & & $x$ & & & & & & & & & & & & $x$ \\
\hline Benefit to society & & & & $x$ & & & & & & & & & & & \\
\hline
\end{tabular}

\subsection{Employee's views}

These studies encompass what different professional groups considered to characterize healthy work environments [15-29], see table 1 . According to these studies the most frequently addressed factors important for a healthy workplace were, in descending order: growth and development of the individual; collaboration/teamwork; employee involvement; pos- 
itive, accessible and fair leader; being treated with respect; positive and social climate; work in line with personal values; recognition; autonomy/empower- ment; skilled communication; safe physical work; and appropriate staffing.

Table 2

Guidelines for factors at work essential for creating a healthy work environment

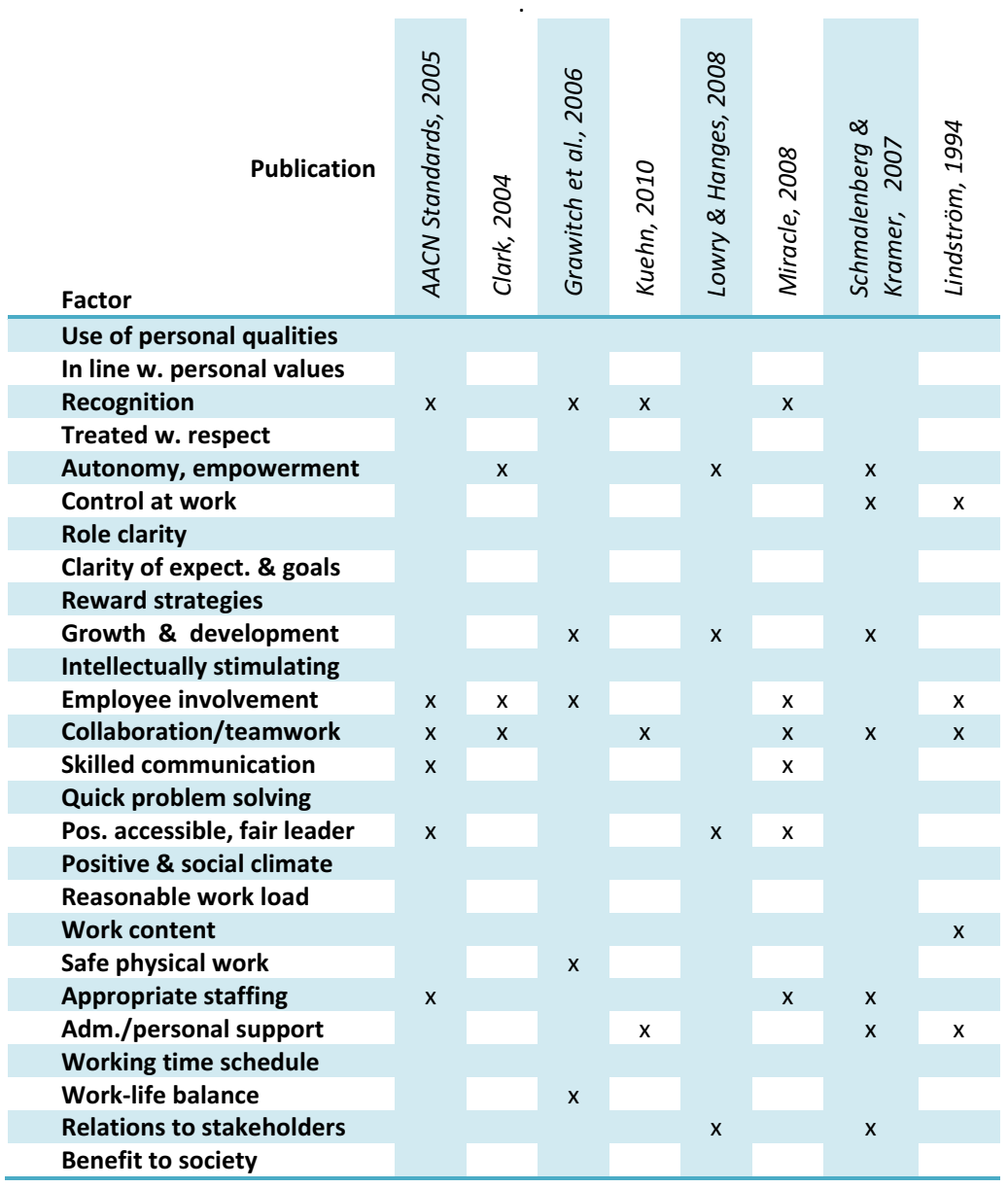

\section{3. "Guidance documents"}

This category includes articles that advocate strategies how to achieve, and opinions about what characterize healthy work environments, but also some models what creates a healthy workplace based on previous research $[8,30-36]$, see table 2 . The most frequently mentioned work place factors important for creating a healthy work environment were, in descending order: collaboration/teamwork; recognition; employee involvement; autonomy/empowerment; growth and development of the individual; positive, accessible and fair leader; appropriate staffing; and administrative and personal support.

Summarizing the results of what employees consider important for a healthy workplace and which factors the guidance documents point out as important the nine most pronounced components identified

to achieve a healthy workplace are, in descending order: collaboration/teamwork: growth and development of the individual; recognition; employee involvement; positive, accessible and fair leader; au- 
tonomy and empowerment; appropriate staffing; skilled communication; and safe physical work.

\section{Discussion}

Despite an extensive and inclusive search only one study explicitly dealing with indicators of healthy work environment was identified. Because of the lack of indicator studies it felt natural to include other studies in the field which could help to define the notion 'healthy workplace' and give a base for future research. The included studies either investigated employee's view of what constitute a healthy workplace or were guidelines for how to create such a workplace.

Ideally an indicator or set of indicators for healthy work environments would be all inclusive and based on evidence, preferably longitudinal studies. Considering this, the results of the present study was meager. A contributing factor for this could be that work environment issues are multi-factorial and complicated to research. As this study has shown there are probably a combination of different factors contributing to a healthy workplace and to find one single indicator for this might be very difficult. Wilson et al. [9] note, 'although several authors have tried to identify and describe the job and organizational characteristics associated with healthy organizations, there has been relatively little direct empirical research and no systematic analysis of a model of healthy work organization conducted to date'.

A general reflection is that in most of the studies investigating healthy organizations exposures to biomechanical factors at work play a subordinate role, in many cases total absence. An explanation might be that these studies are conducted by researches representing social sciences being more focused on psycho-social issues as predictors of well-being. Considering that work related musculoskeletal disorders are a major health issue in most countries and that physical ergonomics can play an important role both for health and productivity, this calls for a multidisciplinary approach in future research on healthy work organizations.

The studies exploring what factors employees consider as crucial for considering the workplace as 'healthy' are mainly qualitative studies investigating the views of employees in different professions as well as at different hierarchical job levels. This is a substantial contribution to our knowledge. However disproportionately many of the studies in this catego- ry deal with health care workers and their work environments, particularly in Northern America, which might have biased the results of this review. More studies from other areas of working life are wanted. Having taken this proviso, it is striking how some factors frequently recur indicating the importance these seem to have.

In general, the 'guidance documents' studies are of somewhat lower scientific quality, e.g. the methods are often inadequately reported or the reviews underpinning the recommendations more of a narrative character, but there are also documents relying on a solid base of science. In some cases the guidance documents seem to have a hidden political agenda aiming at improving the working conditions e.g. for nurses. If this is the case, the objectivity might have been blurred, in order to achieve certain professional goals or benefits. As these studies don't contradict findings from the ones based on original research they were considered to have some empirical value and were included.

\section{Conclusion}

In conclusion this systematic review shows that it would be beneficial for further research to come to some consensus about the concept of healthy work environment/workplace/work organization, and second to put forward longitudinal studies testing some of the models proposed in the literature. To make the idea of a healthy workplace a successful course of action for a sustainable working life there also has to be some well designed practical tools to assess such a work place or the impact of it on the employees.

\section{Acknowledgement}

This study was funded by the Swedish Work Environment Authority. However, its contents are solely the responsibility of the authors and do not necessarily represent the official views of the authority.

\section{References}

[1] Sveriges officiella statistik. Arbetsorsakade besvär 2010 (Work-Related Disorders 2010). Arbetsmiljöstatistik. Stockholm: Arbetsmiljöverket och Statistiska centralbyrån (Swedish Work Environment Authority and Statistics Sweden) 2010. Report No.: 2010:4. 
[2] Griffiths A. Designing and managing healthy work for older workers. Occupational Medicine. 2000;50(7):473-7.

[3] Svartengren M, Ahlberg G, Alberyd J, Bengtsson F, Bergman B, Ekenvall L, et al. Hälsa och framtid - ett forskningsprojekt om långtidsfriska företag [Health and Future - a research project on long-term healthy business]: Karolinska Institutet, Uppsala universitet, Stockholms Läns Landsting; 2008. Available from: http://www.folkhalsoguiden.se/halsaochframtid.

[4] Black C. Working for a healthier tomorrow. Dame Carol Black's review of the health of Britain's working age population. London 2008.

[5] European Agency for Safety and Health at Work. Affärsmässiga fördelar med en god arbetsmiljö (The business benefits of good occupational safety and health). http://oshaeuropaeu/sv/publications/factsheets/77. Bilbao: Europeiska arbetsmiljöbyrån; 10/02/2011.

[6] Arbetsmiljöpolitiska kunskapsrådet. SOU 2009:47 God arbetsmiljö - en framgångsfaktor? Stockholm: Fritze; 2009.

[7] Danna K, Griffin RW. Health and well-being in the workplace: a review and synthesis of the literature. Journal of Management 1999;25:357-84.

[8] Grawitch MJ, Gottschalk M, Munz DC. The path to a healthy workplace: A critical review linking healthy workplace practices, employee well-being, and organizational improvements. Consulting Psychology Journal. 2006;58(3):129-47.

[9] Wilson MG, DeJoy DM, Vandenberg RJ, Richardson HA, McGrath AL. Work characteristics and employee health and well-being: Test of a model of healthy work organization. Journal of Occupational \& Organizational Psychology. 2004;77:565-88.

[10] Styrmedelsutredningen. SOU 2009:97 Marknadsorienterade styrmedel på arbetsmiljöområdet. Slutbetänkande av styrmedelsutredningen. Stockholm 2009.

[11] Sainforth F, Karsh B-T, Booske B, Smith M. Applying quality improvement principles to achieve healthy work organizations. The Joint Commission Journal on Quality Improvement. 2001;27:469-83.

[12] Sauter S, Lim S, Murphy L. Organizational health: A new paradigm for occupational stress research at NIOSH. Japanese Journal of Occupational Mental Health. 1996;4:248-54.

[13] Network on Development Evaluation (OECD/DAC). Glossary of key terms in evaluation and results based management (2002). Stockholm: SIDA 2007.

[14] Nigam JAS, Murphy LR, Swanson NG. Are Stress Management Programs Indicators of Good Places to Work? Results of a National Survey. International Journal of Stress Management 2003;10(4):345-60.

[15] Agervold M. Healthy Work in a Psychosocial Perspective. Nordisk Psykologi. 1991;43(4):249-73.

[16] Aronsson G, Bejerot E, Harenstam A. Healthy work: Ideal and reality among public and private employed academics in Sweden. Public Personnel Management. 1999;28(2):197215.

[17] Baptiste NR. Fun and well-being: insights from senior managers in a local authority. Employee Relations. 2009;31(6):600-12.

[18] Heath J, Johanson W, Blake N. Healthy work environments: a validation of the literature. The Journal of nursing administration. 2004;34(11):524-30.

[19] Hjalmers K, Soderfeldt B, Axtelius B. Healthy work for female unpromoted general practice dentists. Acta Odontologica Scandinavica. 2004;62(2):107-10.
[20] Kroth M, Boverie P, Zondlo J. What Managers Do to Create Healthy Work Environments. Journal of Adult Education. 2007;36(2):1-12.

[21] Lindin-Arwedsson I, Roos S, Björklund A. Constituents of Healthy Workplaces. Work. 2007;28(1):3-11.

[22] Lowe GS, Schellenberg G, Shannon HS. Correlates of employees' perceptions of a healthy work environment. American Journal of Health promotion 2003;17(6):390-9.

[23] MacDermid JC, Geldart S, Williams RM, Westmorland M, Lin CY, Shannon H. Work organization and health: a qualitative study of the perceptions of workers. Work 2008;30(3):241-54.

[24] Nilsson K, Hertting A, Petterson IL. "It depends on us": employee perspective of healthy working conditions during continual reorganisations in a radiology department. Work 2009;33(2):191-200.

[25] Parsons ML, Cornett PA, Burns AL. A healthy emergency department workplace: the staff describe it. Topics in Emergency Medicine. 2005;27(3):198-205.

[26] Parsons ML, Cornett PA, Golightly-Jenkins C. Creating healthy workplaces: Laying the groundwork by listening to nurse managers. Nurse Leader. 2006;4(3):34-9.

[27] Thomsen S, Dallender J, Soares J, Nolan P, Arnetz B. Predictors of a healthy workplace for Swedish and English psychiatrists. The British journal of psychiatry. 1998;173:80-4.

[28] Wreder Å, Gustavsson M, Klefsjö B. Management for sustainable health: A TQM-inspired model based on experiences taken from successful Swedish organizations. International Journal of Quality \& Reliability Management. 2008;25(6):561-84.

[29] Arnetz B, Blomkvist V. Leadership, mental health, and organizational efficacy in health care organizations. Psychosocial predictors of healthy organizational development based on prospective data from four different organizations. Psychotherapy and psychosomatics. 2007;76(4):242-8.

[30] American Association of Critical-Care N. AACN standards for establishing and sustaining healthy work environments: a journey to excellence. American Journal of Critical Care. 2005;14(3):187-97.

[31] Clark PR. An emergency department staff tackles the healthy workplace initiative: a staff nurse perspective. Topics in Emergency Medicine. 2004;26(4):305-11.

[32] Kuehn MB. Creating a healthy work environment for nursing faculty. Creative nursing. 2010;16(4):193-7.

[33] Lindstrom K. Psychosocial criteria for good work organization. Scandinavian journal of work, environment \& health. 1994;20 123-33.

[34] Lowry CB, Hanges PJ. What is the Healthy Organization? Organizational Climate and Diversity Assessment: A Research Partnership. portal: Libraries and the Academy. 2008;8(1):1-5.

[35] Miracle VA. A Healthy Work Environment. Dimensions of Critical Care Nursing. 2008;27(1):42-3.

[36] Schmalenberg C, Kramer M. Types of intensive care units with the healthiest, most productive work environments. American Journal of Critical Care. 2007;16(5):458-68. 